\title{
Multiscale variability of the Chaetognatha along a Caribbean reef lagoon system
}

\author{
Edgar Tovar ${ }^{1,2}$, Eduardo Suárez-Morales ${ }^{1, *}$, Laura Carrillo $^{1}$ \\ ${ }^{1}$ El Colegio de la Frontera Sur (ECOSUR), Av. Centenario Km. 5.5, Chetumal, Quintana Roo 77014, Mexico \\ ${ }^{2}$ Present address: Centro de BioCiencias (CenBio), Universidad Autónoma de Chiapas, Carr. Tapachula-Puerto Madero, \\ Tapachula, Chiapas 30700, Mexico
}

\begin{abstract}
We studied the distributional patterns of the chaetognath community along a large reef system of the western Caribbean during 3 seasons using a multiscale hierarchical sampling design. Hydrographical and biological parameters were measured at 3 different reef lagoons (100 km scale) and in a field of $10 \mathrm{~km}$ at each lagoon. Biological data were analyzed using a nested multivariate analysis of variance, and hydrographical data were analyzed with T-S graphics. Results showed seasonal differences of both hydrographical and biological data. Spatially, the chaetognath composition appeared to be relatively homogeneous over the $100 \mathrm{~km}$ scale at least during dry and rainy seasons, when neritic forms are widely dominant; however, during the season of northerlies a shift in the chaetognath composition occurred, with oceanic forms becoming dominant. Hydrographical conditions and chaetognath composition were variable within lagoons. It is inferred that the observed seasonal patterns of the reef chaetognath community at the $100 \mathrm{~km}$ scale is affected by: (1) the largescale physical processes including the seasonal strength of the Yucatan Current and the variation of the sea level within the lagoons and (2) the local geomorphology of the reef lagoon, including the structure and height of the reef crest. The differential effect of these factors in the 3 reef lagoon systems determines the extent of the oceanic influence and structural profile of the chaetognath community. Multiscale studies on other taxa and a quantitative evaluation of predation in the community should be developed in order to provide significant insights into the processes involved in the dynamics of the reef zooplankton. Understanding the local variability patterns will help in developing effective management and protection actions for the reef ecosystem.
\end{abstract}

KEY WORDS: Zooplankton ecology $\cdot$ Chaetognaths $\cdot$ Coral reef

\section{INTRODUCTION}

Marine zooplankton exhibits variable patterns that are generated and maintained by the coupling of physical and biological processes that take place at distinct spatial and temporal scales (Daly \& Smith 1993, Bochdansky \& Bollens 2004, Mann \& Lazier 2006, Tzella \& Haynes 2007). The hierarchy paradigm provides guidelines for defining the functional components of a system and how they relate to one another at different scales. Complex stable systems are often hierarchical (Allen \& Star 1982), and their temporal and spatial scales are connected; therefore, physical and biological processes acting at a large spatial scale are related to structures at smaller scales and vice versa (Levin 1992).

Nested patchiness is a common feature of marine zooplankton communities; this spatial heterogeneity occurs on a hierarchical continuum of scales ranging from centimeters (microscale) to thousands of kilometers (megascale) and from minutes to days or weeks (Pinel-Alloul 1995, Bochdansky \& Bollens 2004). The zooplankton spatial heterogeneity defines the structure and dynamics of the marine biota of different environments (Saiz \& Kiørboe 1995, Noda et al. 1998, Folt \& Burns 1999).

Because of the relevance and peculiar features of reef-related environments, a quantitative description 
of the variability of the zooplankton community is needed to provide significant insights into the fundamental structure of this complex environment. Reef lagoons are deemed a physical, chemical, and biological interface between marine and the coastal environments. Because of the narrowness of the continental shelf along the northwestern Caribbean reef system, a mixture of neritic and oceanic zooplankters is found in the reef lagoon year-round (Suárez-Morales \& Gasca 1996, 2000). Some surveys have suggested that the structure of the zooplankton community is not homogeneous along this reef lagoon system (SuárezMorales \& Gasca 1996, 2000, Alvarez-Cadena et al. 1998), but this variability has not been explored within a multiscale frame. Chaetognaths, our target group, have been reported as indicators of hydrographical conditions and features in different geographical areas (Nagai et al. 2006).

The main goal of this study was to describe patterns of temporal and multiscale spatial variability of the Chaetognatha along the northwestern Caribbean reef system by using a hierarchical model and sampling design to perform structural comparisons among 3 selected reef lagoons. Also, in order to explain chaetognath variability, we discuss the local processes involved in it by evaluating the hydrography, reef geomorphology, and large-scale circulation.

\section{MATERIALS AND METHODS}

Study area. The Caribbean fringing coral reef system is the world's second largest and stretches from the northern part of the Yucatan Peninsula, Mexico (Fig. 1), to Honduras in Central America. The area has 3 well defined seasons: (1) dry (DS), from March to June, with minimum precipitation and dominant trade winds; (2) rainy (RS), from July to October, high precipitation with frequent storms and dominant trade winds; and (3) 'Nortes' season (NS), from November to February, with northerly winds, scarce precipitation, and relatively low temperatures (Merino \& Otero 1991).

This reef system has 4 geomorphological regions (Nùñez-Lara et al. 2005), of which 3 were selected to evaluate our largest scale (100 km; Fig. 1C): (1) northern zone, with submerged reef crests and discontinu-

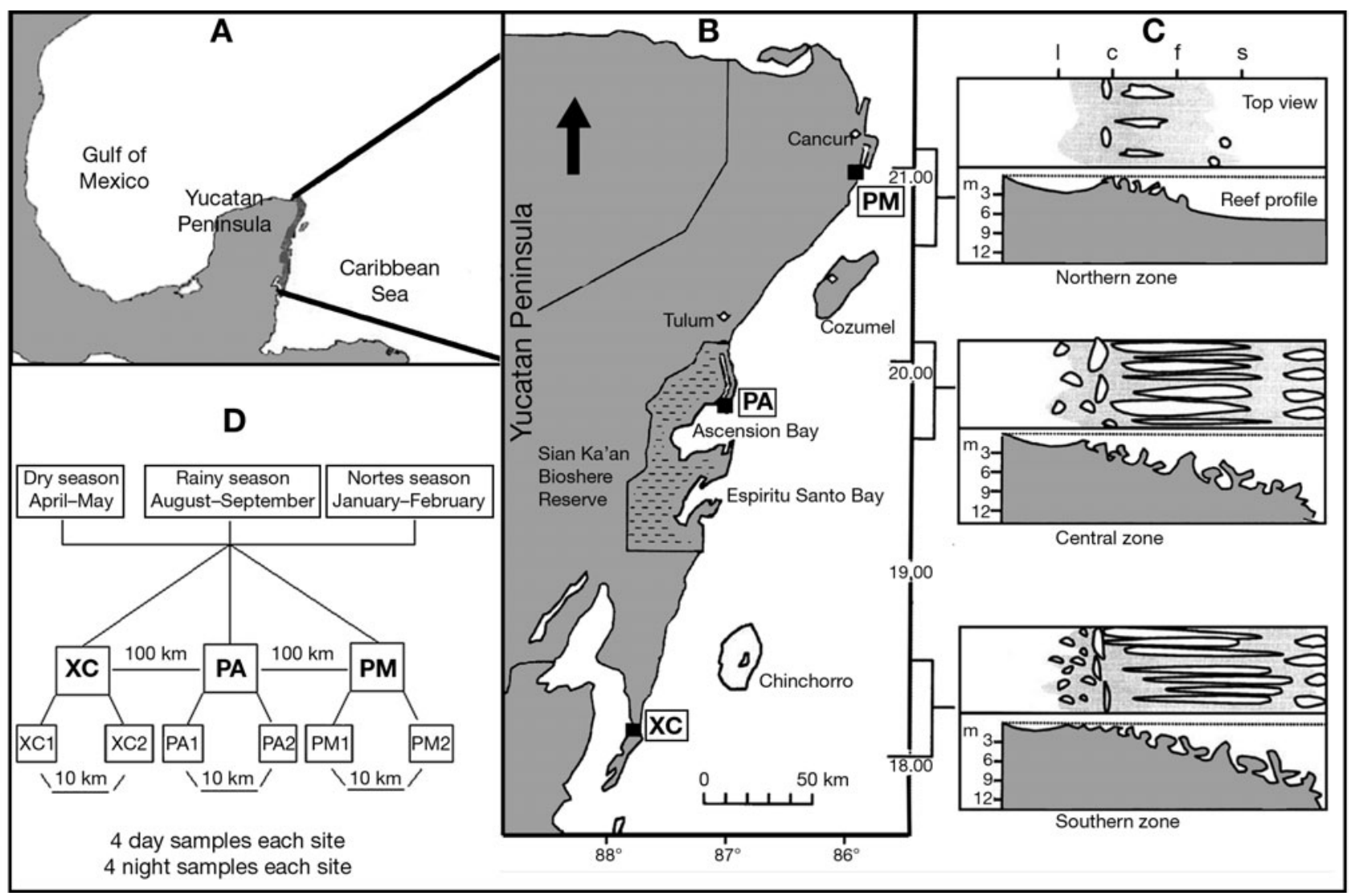

Fig. 1. (A) Surveyed area in the Northwestern Caribbean. (B) Surveyed reef systems along the Mexican Caribbean coast: PM, Puerto Morelos; PA, Punta Allen; XC, Xcalak. (C) Geomorphology of the 3 selected reef systems. (D) Sampling design model, as explained in 'Materials and methods'. B and C modified from Nùñez-Lara et al. (2005) 
ous reef formations along the coast. The reef site selected in this zone was Puerto Morelos Reef (PM), in the National Marine Protected Park of Puerto Morelos $\left(20^{\circ} 48^{\prime} 33^{\prime \prime} \mathrm{N}, 86^{\circ} 46^{\prime} 38^{\prime \prime} \mathrm{W}\right)$. (2) Central zone, with highly developed coral reef structures and emerged crests; the area is influenced by an adjacent bay. The surveyed reef site was Punta Allen Reef (PA), which is part of the Sian-Ka'an Biosphere Reserve $\left(19^{\circ} 36^{\prime} 41^{\prime \prime} \mathrm{N}, 87^{\circ} 26^{\prime} 34^{\prime \prime} \mathrm{W}\right)$. (3) Southern zone, with reef formations represented by spurs and grooves. Spurs are extensive and high, typically with emerged crests; reef structures are complex and largely continuous. The selected reef was Xcalak (XC), which is part of a National Marine Protected Park (18 $28^{\circ} 00^{\prime \prime} \mathrm{N}$, $87^{\circ} 48^{\prime} 48^{\prime \prime} \mathrm{W}$ ) (Fig. 1).

Sampling design. We used an arbitrary arrangement of related hierarchical scales based on a basic magnitude order. The model consists of a $3 \times 3 \times 2$ and 8 replicates (see Fig. 1D). The first factor (Season) comprised 2 mo of each season of a 1 yr cycle: DS (April and May 2005), RS (August and September 2005), and NS (January and February 2006). The spatial component (Reef) included the 3 geomorphological reef systems, each separated from the other by approximately $100 \mathrm{~km}$ (large scale). A third, nested factor included 2 sampling stations (Site) at each reef lagoon (XC1, 2; PA1, 2; PM1, 2), each separated by $10 \mathrm{~km}$ from the other (medium scale). In order to include nictemeral variability, samples were taken at both noon and midnight at each site under full moon conditions only; every tow had a replicate, thus, 8 samples were obtained at each site, and up to 144 samples were collected and analyzed.

Zooplankton was collected by hauling (10 min, horizontally) a standard plankton net (mesh size: $0.3 \mathrm{~mm}$, $45 \mathrm{~cm}$ mouth diameter) at each site. A digital flowmeter was attached to the net in order to measure the volume of water filtered; the mean water filtered was $98.7 \mathrm{~m}^{3}$ per haul. Samples were fixed and preserved in a $10 \%$ buffered formaline solution. Chaetognaths were sorted from the entire original sample and identified to species; their abundance was standardized to inds. $100 \mathrm{~m}^{-3}$.

Temperature $\left({ }^{\circ} \mathrm{C}\right.$ ) and salinity (psu) were measured at each reef site during the biological sampling. Hydrographical data were obtained with a Seabird SBE-19 CTD at stations every kilometer along a $10 \mathrm{~km}$ transect (between sampling sites).

Data analysis. Two sets of data were analyzed: biological (chaetognath abundance) and hydrographical, both over an area of $10 \mathrm{~km}$ at each reef lagoon. Chaetognath abundances were root-transformed and analyzed according to the 3 factor hierarchical experiment design using permutational multivariate analysis of variance (PERMANOVA; Anderson 2001). This non- parametric multivariate method is based on permutation tests and allows additive partitioning of variation for complex models. The statistical test is a multivariate analysis analogue to Fisher's F-ratio; it is calculated directly from any symmetrical distance, similarity or dissimilarity matrix, using permutations to obtain p values (Anderson 2001, 2005). Hence, the BrayCurtis index was used to build the similarity matrix and it is given by:

$$
\mathrm{BC}_{i j}=\sum \frac{|n i k-n j k|}{(n i k+n j k)}
$$

where $\mathrm{BC}_{i j}$ is the similarity between the $j$ th and $k$ th sites; nij represents the abundance of the $i$ th species in the $j$ th site. Measures of multivariate variability at temporal and spatial scales were calculated from the mean squares of the PERMANOVA by using a direct multivariate analogue to the usual ANOVA estimator variance components (Anderson et al. 2005). Pair-wise tests were made for each pair of levels and factors. Salinity and temperature data were processed using the software provided by the manufacturer (SBEData Processing_Win32). Temperature-salinity (T-S) diagrams were analyzed for each reef and season.

\section{RESULTS}

\section{Hydrography of the reef lagoons}

Temperature and salinity values of the 3 reef lagoons are shown in T-S diagrams for each season (Fig. 2AC). In $\mathrm{XC}$, temperatures ranged from 26.6 to $30.2,29.6$ to 31.5 , and 18.25 to $25.7^{\circ} \mathrm{C}$ during $\mathrm{DS}, \mathrm{RS}$, and NS, respectively. Salinity values ranged from 30.27 to $37.99,28.35$ to 35.97 , and 34.83 to 36.00 psu during DS, RS, and NS, respectively. In PA, temperatures ranged from 26.5 to $29.4,29.7$ to 31.1 , and 22.6 to $25.6^{\circ} \mathrm{C}$ in DS, RS and NS, respectively. Salinity values ranged from 34.57 to $37.99,32.99$ to 36.48 , and 33.96 to 36.06 psu in DS, RS and NS, respectively. In PM, temperatures ranged from 26.5 to $27.58,29.1$ to 30.4 , and 21.6 to $24.5^{\circ} \mathrm{C}$ in DS, RS, and NS, respectively. Salinity values ranged from 34.42 to $37.5,35.27$ to 36.50 , and 34.34 to $36.9 \mathrm{psu}$ in DS, RS, and NS, respectively.

In general, hydrographical data showed differences between lagoons (100 km scale); these were relatively weaker during RS (Fig. 2B). Lowest average temperatures were recorded during NS, particularly at PM. During RS and NS, salinity was consistently below 36. The highest salinity (37.99) was recorded at XC and PA during DS. The maximum temperature $\left(31.5^{\circ} \mathrm{C}\right)$ and the lowest salinity of the RS (32.99) were observed at XC.

Inside each lagoon (10 km scale) seasonal temperature differences were relatively homogeneous (Figs. 2D-F), 

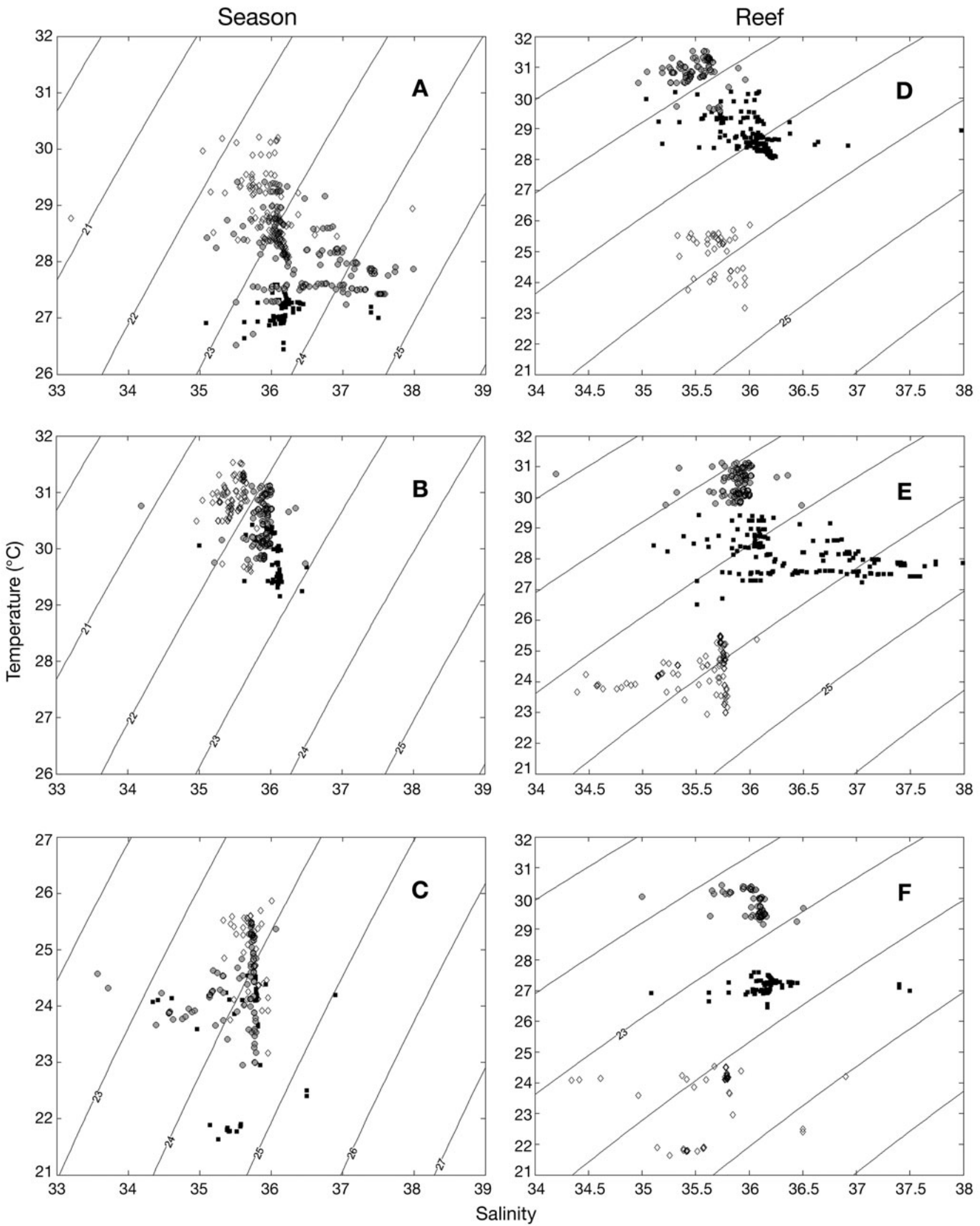

Fig. 2. T-S diagrams for each season: (A) dry season (DS); (B) rainy season (RS); (C) Nortes season (NS)., Xcalak (XC); $\bullet$, Punta Allen

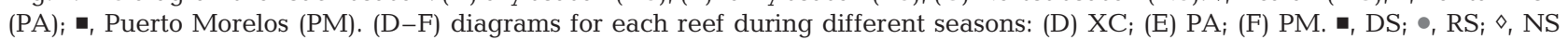


whereas salinity showed high intra-lagoonal variability but no clear seasonality. Each of the 3 reef lagoons presented differences in temperature and salinity larger than those observed at the $100 \mathrm{~km}$ scale.

\section{Chaetognath composition}

Up to 48138 specimens of Chaetognatha from the 3 reef lagoon sites were examined. Seven species were identified: Ferosagitta hispida, Flaccisagitta hexaptera, Flaccisagitta enflata, Krohnitta pacifica, Parasagitta tenuis, Serratosagitta serratodentata, and Pterosagitta draco. Based on different studies of the western Caribbean chaetognath fauna (Gasca et al. 1996, Alvarez-Cadena et al. 1998, Hernández-Flores 2003), the species recorded were categorized as neritic or oceanic forms. F. hispida and P. tenuis were considered neritic forms; they have been found to be consistently denser in coastal-neritic areas of the western Caribbean (Alvarez-Cadena et al. 1996a). Likewise, F. enflata, S. serratodentata, P. draco, and F. hexaptera were deemed as oceanic forms in the surveyed area, although some of these species have also been recorded from coastal-neritic environments in other geographical areas (Giesecke \& González 2004). Overall, the chaetognath community of the surveyed reef lagoons was largely dominated by 2 species, F. hispida and $F$. enflata; together, they represented $87 \%$ of the total chaetognath catch.

The total seasonal abundance of both groups of species (neritic and oceanic) is presented in Fig 3. During

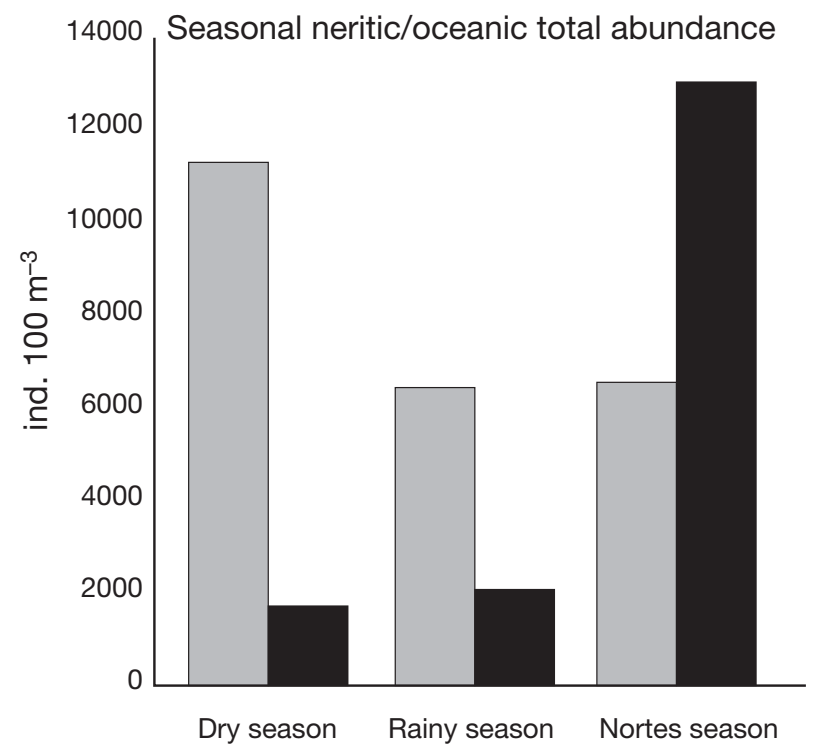

Fig. 3. Seasonal total abundance of neritic vs. oceanic species in the 3 reef lagoons. Abundance (ind. $100 \mathrm{~m}^{-3}$ ). White bars, neritic species; black bars, oceanic species
DS, the neritic forms were dominant in the 3 lagoons $(86.7 \%$ of the chaetognath numerical abundance, 11255 ind.). In RS, the neritic forms retained the dominance but with a lower proportion (75\%, 6447 ind.). In both DS and RS, the oceanic forms occurred with low relative abundance. A major shift was observed during NS, when the oceanic forms became most abundant (66.4\%, 13020 ind.).

During DS, the neritic Ferosagitta hispida was the most abundant species, whereas Flaccisagitta enflata, the most abundant oceanic form in the 3 reef lagoons, had relatively low densities. The neritic Parasagitta tenuis showed low densities during this season, being slightly more abundant at $\mathrm{PA}_{;}$the oceanic Pterosagitta draco occurred only at PM with low abundance. During the RS, the abundance of $F$. hispida decreased in the 3 reef systems surveyed but only slightly at PA and $\mathrm{PM}$; at XC it decreased abruptly. The other neritic species, $P$. tenuis, increased in abundance at PA and PM, whereas $F$. enflata increased at $\mathrm{XC}_{\boldsymbol{i}}$ its abundance at PM and PA during this season was similar to that observed in the DS. Other oceanic forms such as Krohnitta pacifica and $P$. draco occurred in different patterns; the former increased in abundance at PA and PM, the latter occurred only at PM. During the NS, the density increase of the oceanic $F$. enflata and $K$. pacifica was sharp at PA and PM; in XC this shift was weaker (Fig. 3). Further, the oceanic species $P$. draco showed its highest abundances during this season and occurred at PA and PM.

The species richness showed some variation. Overall, only 4 species were found at $\mathrm{XC}$, and 3 of them were recorded during the 3 seasons; no oceanic forms were found at $\mathrm{XC}$. In PA, 5 species were found during DS and RS; a sixth species, the oceanic Pterosagitta draco, was recorded only during NS, and Flaccisagitta hexaptera was absent from PA. In PM, 6 species were found during DS and RS, and F. hexaptera occurred during NS only (Fig. 4).

Three different seasonal assemblages were recognized: (1) DS phase: neritic species widely dominant, oceanic forms with low abundance; (2) RS phase: decline of neritic species, oceanic forms retain DS relative abundance; (3) NS phase: oceanic species become dominant, declining of neritic forms.

\section{Spatial and temporal variability}

The PERMANOVA analysis of the chaetognath assemblage (Bray-Curtis index), showed significant variability in the community among seasons (temporal scale), reefs (large scale), and at single sites throughout the seasons. Non-significant values were obtained at $10 \mathrm{~km}$ and among reefs within each season 

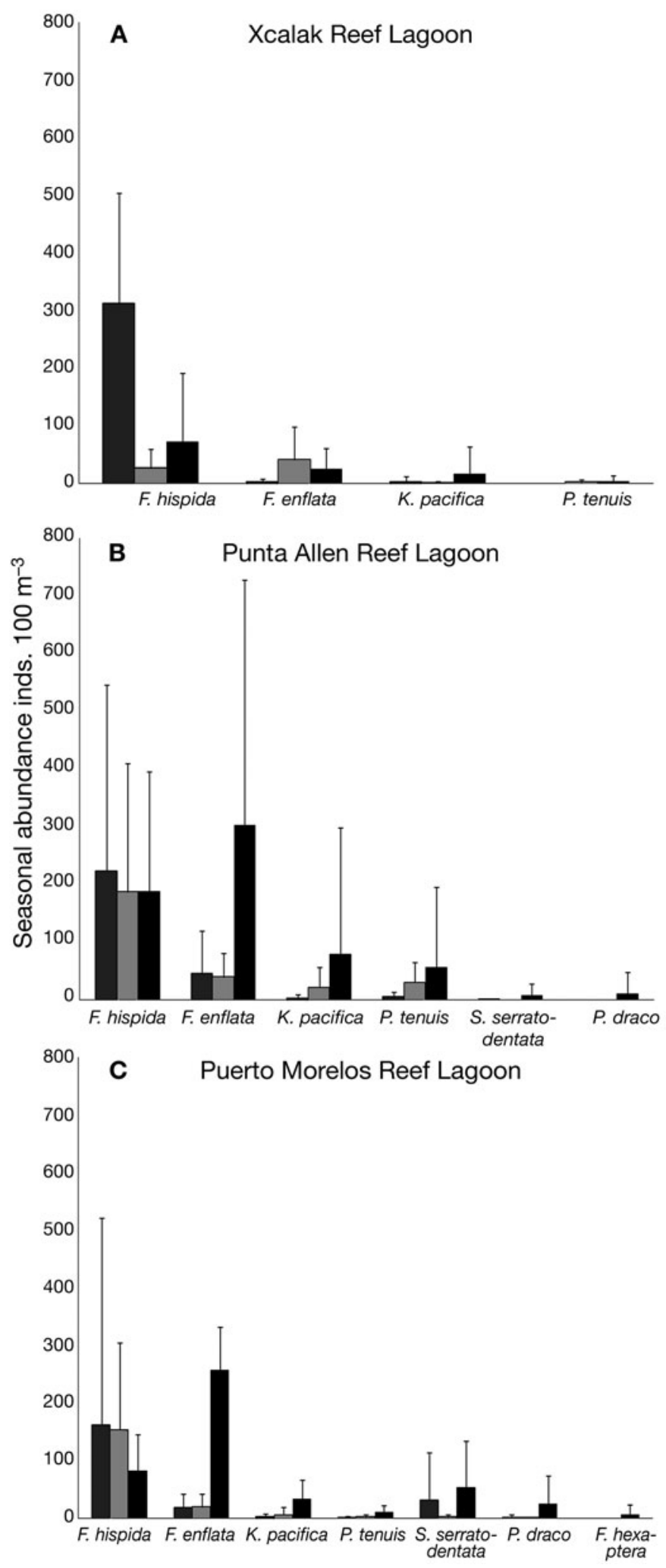

Fig. 4. Seasonal average abundance (ind. $100 \mathrm{~m}^{-3}$ ) of chaetognaths in the 3 reef lagoons. White bars, dry season (DS), gray bars, rainy season, black bars, Nortes season. (A) Xcalak Reef lagoon; (B) Punta Allen Reef lagoon; (C) Puerto Morelos Reef lagoon
(Table 1). The greatest component of variation was residual $(62.5 \%)$, followed by the differences at a large scale (among reef lagoons: 14.5\%), seasons (13.1\%), and sites within the seasons, contributing $8.6 \%$ of the total variability. Sampling sites at each reef during each season contributed little to the observed variation ( $1 \%$ and $0.3 \%$, respectively; Table 1 ).

The high value of the residual component is probably related to (1) the small-scale variability beyond the resolution of our design $(<10 \mathrm{~km})$; it includes biological and physical processes with influence on the structure of zooplankton (Pinel-Alloul 1995, Sampey et al. 2007) and (2) the effect of night and day samples, which incorporate into the model the local nictemeral variability of the chaetognath community. However, this factor was found to be of relatively low impact; day and night abundance data sets were statistically compared and deemed as replicas with no differences between them $(p=0.078)$. This high residual component agrees with the considerable intra-lagoonal (micro- and small scale) hydrographical data dispersion observed during each season.

Pair-wise tests of species composition and abundance between seasons showed main differences between DS and NS ( $p=0.0009)$; however, differences between DS and RS ( $p=0.108)$ or RS and NS ( $p=0.116)$ were not significant. Differences at the large spatial scale were significant (XC-PA, $\mathrm{p}=0.01$; $\mathrm{XC}-\mathrm{PM}, \mathrm{p}=0.001$; PA-PM, $p=0.03)$. The seasonal analysis of sites within lagoons showed differences $(p=0.025)$ between DS and NS in the 3 lagoons. The seasonal analysis of each sampling site showed differences between DS and NS at XC; however, variation between sampling sites at PA were seasonally consistent. The seasonal analysis showed differences only during NS between XC-PM and PA$\mathrm{PM}$ but none between each $\mathrm{XC}$ site during all seasons; at PA and PM seasonal variations were found between sampling sites (Table 2). PM1 also showed differences in DS-NS and RS-NS, whereas site PM2 did not show seasonal differences (Table 3).

\section{DISCUSSION}

Typical salinities in surface oceanic waters of the northwestern Caribbean Sea range between 36.0 and 37.5 (Candela et al. 2003); however, lower salinities have been consistently detected in coastal waters of the same area (L. Carrillo pers. obs.). Our data from the reef lagoons agree with this pattern; salinity averaged below 36 at most sampling sites, thus marking the hydrographical contrast between the oceanic and the coastal-neritic areas.

At the large scale $(100 \mathrm{~km})$, temperature was highest in XC and lowest in PM. Within lagoons, temperature 
Table 1. PERMANOVA results based on overall chaetognath abundances (ind. $100 \mathrm{~m}^{-3}$ ) from the 3 different reef lagoon systems. Significant values of $\mathrm{p}$ in bold

\begin{tabular}{|lccccrrr|}
\hline Source & df & SS & MS & $F$ & p & Variation & \% Proportion \\
\hline Season & 2 & 21939 & 10970 & 5.8056 & $\mathbf{0 . 0 0 2 2}$ & 189.17 & $\mathbf{1 3 . 1}$ \\
Reef & 2 & 22556 & 11278 & 8.9452 & $\mathbf{0 . 0 0 1 2}$ & 208.69 & $\mathbf{1 4 . 5}$ \\
Site (reef) & 3 & 3782.4 & 1260.8 & 1.4003 & 0.3748 & 15.018 & 1.0 \\
Season $\times$ Reef & 4 & 7308.1 & 1827 & 0.96694 & 0.2386 & 3.904 & 0.3 \\
Season $\times$ Site (reef) & 6 & 11337 & 1889.5 & 2.0986 & $\mathbf{0 . 0 1 3 2}$ & 123.64 & $\mathbf{8 . 6}$ \\
Residual & 126 & $1.1345 \mathrm{E} 5$ & 900.37 & & & & \\
Total & 143 & $1.8037 \mathrm{E} 5$ & & & & 100.37 \\
\hline
\end{tabular}

Table 2. p-values of pair-wise tests between pairs of levels of the factors Reef and Sample Site (in parentheses) during each season. Significant values in bold. XC: Xcalak; PA: Punta Allen; PM: Puerto Morelos; DS: dry season; RS: rainy season; NS: Nortes season. Standardized abundance data (ind. $100 \mathrm{~m}^{-3}$ ) were used

\begin{tabular}{|lcc|}
\hline \multirow{2}{*}{ Season } & Reef (Site) & $\mathrm{p}$ \\
\hline \multirow{2}{*}{ DS } & XC-PA & 0.615 \\
& XC-PM & 0.451 \\
RS & PA-PM & 0.619 \\
& XC-PA & 0.377 \\
NS & XC-PM & 0.371 \\
& PA-PM & 0.136 \\
& XC-PA & 0.431 \\
DS & XC-PM & $\mathbf{0 . 0 0 1}$ \\
& PA-PM & $\mathbf{0 . 0 2 5}$ \\
\multirow{2}{*}{ RS } & & \\
& XC (XC1-XC2) & 0.668 \\
& PA (PA1-PA2) & 0.002 \\
NS & PM (PM1-PM2) & 0.023 \\
& XC (XC1-XC2) & 0.736 \\
& PA (PA1-PA2) & 0.021 \\
& PM (PM1-PM2) & 0.018 \\
& XC (XC1-XC2) & 0.081 \\
& PA (PA1-PA2) & 0.329 \\
& PM (PM1-PM2) & 0.329 \\
\hline
\end{tabular}

and salinity showed differences between sampling sites. This intra-lagoonal gradient was observed markedly at PA and PM; it is clear that chaetognaths cope with a wide range of hydrographical variation (18.2 to $31.5^{\circ} \mathrm{C}, 32$ to $37.9 \mathrm{psu}$ ) within the reef lagoons.

Ferosagitta hispida and Parasagitta tenuis are among the most common chaetognath species in neritic-coastal environments of the Caribbean (AlvarezCadena et al. 1996b). In our survey, these species characterized the chaetognath fauna of the reef systems surveyed during DS and RS, whereas Flaccisagitta enflata, considered to have an oceanic affinity in the area (Gasca et al. 1998; Hernández-Flores 2003), was clearly dominant during NS, thus marking an interesting seasonal shift of the chaetognath community. A seasonal increase of the numerical abundance and diversity of other oceanic zooplankters has
Table 3. p-values of pair-wise tests between pairs of levels of season factors in Reefs and Sample Sites (in parentheses). Significant values in bold. XC: Xcalak; PA: Punta Allen; PM: Puerto Morelos; DS: dry season; RS: rainy season; NS: Nortes season. Standardized abundance data (ind. $100 \mathrm{~m}^{-3}$ ) were used

\begin{tabular}{|lcc|}
\hline \multirow{2}{*}{ Reef (Site) } & Season & $\mathrm{p}$ \\
\hline XC & DS-RS & 0.078 \\
& DS-NS & $\mathbf{0 . 0 0 5}$ \\
PA & RS-NS & 0.068 \\
& DS-RS & 0.528 \\
PM & DS-NS & $\mathbf{0 . 0 0 8}$ \\
& RS-NS & 0.847 \\
& DS-RS & 0.725 \\
XC (XC1) & DS-NS & $\mathbf{0 . 0 1 6}$ \\
& RS-NS & 0.121 \\
XC (XC2) & DS-RS & \\
& DS-NS & 0.082 \\
PA (PA1) & RS-NS & $\mathbf{0 . 0 0 2}$ \\
& DS-RS & 0.565 \\
& DS-NS & 0.46 \\
PA (PA2) & RS-NS & $\mathbf{0 . 0 0 9}$ \\
& DS-RS & 0.664 \\
PM (PM1) & DS-NS & 0.118 \\
PM (PM2) & RS-NS & $\mathbf{0 . 0 1 5}$ \\
& DS-RS & $\mathbf{0 . 0 1 2}$ \\
& DS-NS & $\mathbf{0 . 0 0 1}$ \\
& RS-NS & $\mathbf{0 . 0 0 1}$ \\
& DS-RS & 0.236 \\
& DS-NS & 0.143 \\
& RS-NS & $\mathbf{0 . 0 0 7}$ \\
& DS-RS & $\mathbf{0 . 0 0 8}$ \\
& DS-NS & 0.149 \\
& RS-NS & 0.104 \\
& & 0.068 \\
\hline \multirow{2}{*}{ PM } & \\
& & \\
& & \\
& &
\end{tabular}

been observed in the Mexican Caribbean reef lagoon during NS (Alvarez-Cadena et al. 1998, SuárezMorales \& Gasca 2000). The local distribution and seasonal abundance of both F. hispida and F. enflata could be useful in tracing local variations of neritic or oceanic conditions across the reef lagoon-shelfoceanic gradient.

The general structure of the reef lagoon chaetognath assemblages in the western Caribbean reef sys- 
tem could be described as homogeneous at the largest spatial scale at least during the DS and RS; it is characterized by the dominance of Ferosagitta hispida and Flaccisagitta enflata. However, the NS chaetognath community shows diverging features even among the reef lagoon sites. The 3 sites also differed in terms of oceanic influence as derived from the affinity and structure of its chaetognath community; PM was the reef system with the strongest oceanic influence, whereas XC maintained a neritic profile. Hence, it is likely that hydrographically, PM is more influenced by oceanic waters than the other reef systems along the Mexican Caribbean coast. Further hydrographical studies are needed to prove this inference. Latitudinal differences in species richness and abundance could also favor the structural divergence of the XC chaetognath community with respect to the other 2 sites.

The chaetognath community of the 3 reef sites varied seasonally; contrasting values were found between DS and NS. This seasonal effect was observed at both large and small scales and, at least partially, it could be explained by changes in temperature and salinity; however, the broadest variation of these parameters occurred between RS and NS, thus suggesting that these were not the main factors of variation in the chaetognath community. The XC intra-lagoonal chaetognath community remained stable during the 3 seasons; PA and PM varied during both DS and RS. This variation is attributed to the temporal effect resulting from the location of the sampling sites and the local reef geomorphology (see 'Geomorphology of the reef sites' below). The low day/night variation observed in our samples was attributed to the shallowness of the reef lagoons (1.5 to $3.5 \mathrm{~m}$ ).

The large-scale variability of the reef lagoon chaetognath community could be determined by the combination of 2 main factors: (1) large-scale hydrographical processes, by which the extent of the oceanic influence in the reef lagoon is determined, as explained in 'Large-scale hydrography' below, and (2) the local geomorphology of the reef sites. Both factors have been hitherto described as determinant of zooplankton distribution at medium and large scales in different marine environments (Haury et al. 1978, Sabatès et al. 1984, Daly \& Smith 1993, Pinel-Alloul 1995). Biological factors such as predation could also explain part of the local patterns and site-to-site variation of the chaetognath community. The available trophic models from the mature, well-developed coral reef systems of the Mexican Caribbean confirm that predation is one of the main mechanisms for biomass regulation (AlvarezHernández 2003). Coral reef fish feed on chaetognaths and other zooplankters (Sampey et al. 2007); a recent trophic model of the Caribbean reef system proposed by Arias-González (1998) indicates that fish diversity is highest at Mahahual (corresponding to our XC area), but trophic activity and fish abundance is highest off Boca Paila (corresponding to our PA area). Hence, the local differences in potential predation and survival rates are inferred as relevant factors that could also determine the structural variation of the chaetognath community along the Caribbean reef system. This aspect should be surveyed in more detail through a complete trophic modeling of the local zooplankton community.

\section{Large-scale hydrography}

Along the Caribbean fringing reefs, waves overtop the reef crest; the resulting inflow is considered to be the main mechanism of internal circulation in the reef lagoon (Roberts et al. 1992, Hearn 1999). In fact, surface waves contribute $87 \%$ of the variability of the transport in the PM reef lagoon and break over the reef crest, thus generating a unidirectional water flow into the lagoon, whose intensity is dependent on the wave height (Coronado et al. 2007). This process induces accumulation of water in the lagoon and raises its level, thus causing the excess water to outflow through the inlets (reef channels). Internal currents are driven by the sea level difference between the reef lagoon and the adjacent oceanic waters. The residence time (RT) of water in the lagoon also depends on the fluctuation and intensity of the Yucatan Current (YC). The YC is strongest (up to $2 \mathrm{~m}$ $\mathrm{s}^{-1}$ ) from April to November and weakest in late winter $\left(0.9 \mathrm{~m} \mathrm{~s}^{-1}\right)$. RT increases when winds are weak (DS and RS) and extended periods of low waves occur due to the YC intensification (i.e. reducing the sea level and the surface waves). RT decreases when the surface waves and sea level rise as a result of the relative weakness of the YC during NS. The expected effect of these processes on the chaetognath community structure in the reef lagoons would be: (1) a stronger oceanic overall profile of the group, with an increase in the numerical abundance of oceanic forms and relatively low occurrence of neritic species during the weak YC period (NS) and (2) increasing abundance of neritic species and less abundant oceanic forms during the YC intensification (RS, DS). Our results largely agree with this pattern. However, in the case of XC, in the south, oceanic circulation processes differ from those affecting PM and PA. Mesoscale features were observed off the XC area by current measurements, satellite images, and numerical models; the effect of the $\mathrm{YC}$ in this part of the Caribbean coast is not clear (L. Carrillo pers. obs.). 


\section{Geomorphology of the reef sites}

Together with the hydrodynamic regime, the local transportation of oceanic zooplankton onto the reef lagoon seems to depend also on the structure and development of the reef crest. The effect of these processes on reef lagoon chaetognaths is variable along the reef system. Oceanic chaetognaths were most abundant during NS at PM, the site where the reef is less developed. It is presumed that the increased sea level height during this season favored the transport of zooplankton into the lagoon overtopping the crest. The crossing rate over the reef crest is related to its development and height, thus becoming a source of physical and biological difference among the lagoons. In the surveyed area, the reef structure at our large scale shows a north-south gradient of increasing development and complexity (Núñez-Lara et al. 2005). In PM the reef is discontinuous, with submerged crests, whereas at PA and XC the crests are emerged and relatively continuous.

The surf zone or high turbulence zone caused by the wave interaction with the reef crest could hinder the exchange of zooplankton over the crest. In fact, some zooplankters are damaged and die in excessively turbulent environments (Graham et al. 2001) or tend to swim away from them (Mackas et al. 1993, Genin et al. 2005, Hogan \& Mora 2005). The soft-bodied oceanic chaetognaths could be damaged by the extreme turbulence created by the reef crest, especially during low sea level and at reef areas with a well-developed crest. Our results show that during low sea level seasons (DS, RS), neritic forms are dominant and the chaetognath community was not significantly different among lagoons (100 km scale), but differences were detected at a small scale $(10 \mathrm{~km})$, especially in PA and PM, where a no-reef crest condition was related to one of the sampling sites. Apparently, this condition favored the local occurrence of most of the oceanic species recorded at both sites and also the highest species richness at PM. The relevance of reef geomorphology has also been outlined in studying the distribution of Caribbean reef fishes (Núñez-Lara et al. 2005).

One of the fundamental and yet poorly understood aspects of coral reef ecosystem dynamics, and indeed of marine ecosystem function in general, is larval dispersal, recruitment, and transport. Many Caribbean reef-associated organisms, including regionally important species such as corals, lobsters Panulirus argus, molluscs (e.g. Strombus gigas), and sea urchins Diadema antillarum, reproduce by releasing free-swimming gametes or early larvae into the water column. Presumably, larval and zooplankton dispersal and recruitment processes play a key role in the population structure and ecosystem function. Coupling multiscale zooplankton and hydrographical studies is an important step in understanding the relative importance of local versus remote sources of organisms, and to reveal the physical and biological mechanisms involved in these processes. These aspects are most relevant in studies of population dynamics, fisheries, and most importantly, in the conservation and management of tropical marine reserves such as those surveyed; protected and unprotected reef areas seem to have detectable structural and trophic differences in the Mexican Caribbean (Arias-González 2005). Hydrographical processes and geomorphological features have different seasonal effects on the reef zooplankton community at a given site, with changes that can be traced through the structural profile of the community and the oceanic influence in the system. Hence, both management and conservation surveys/actions on the reef areas should consider this variability.

Acknowledgements. We gratefully acknowledge J. AlvarezCadena, I. Castellanos, A.R. Almaral, R. Herrera, S. Morales, R.M. Hernández, A. Ramírez, and J.A. Cohuo for field assistance. Our gratitude to M. García (CONANP) and E. Palacios (Universidad de Guadalajara) for support and loan of oceanographic gear. Thanks to T. Garfias and E. Palacios for comments. This contribution is part of the doctoral dissertation by E.T. Logistical and financial support was provided by ECOSUR-Chetumal. The comments from 3 anonymous reviewers greatly improved an earlier version of this work.

\section{LITERATURE CITED}

Allen TFH, Star TB (1982) Hierarchy-perspective for ecological complexity. University of Chicago Press, Chicago, IL

Alvarez-Cadena JN, Suárez-Morales E, McLelland JA (1996a) Observations on an isolated population of Sagitta hispida Conant (Chaetognatha) in a tropical lagoon system of northeast Yucatan (Mexico). Gulf Res Rep 9:197-204

Alvarez-Cadena JN, Islas-Landeros ME, Suárez-Morales E (1996b) A preliminary zooplankton survey in a Mexican Caribbean eutrophic coastal lagoon. Bull Mar Sci 58: $694-708$

Alvarez-Cadena JN, Suárez-Morales E, Gasca R (1998) Copepod assemblages from a reef-related environment in the Mexican Caribbean Sea. Crustaceana 71:411-433

Alvarez-Hernández JH (2003) Trophic model of a fringing coral reef in the Southern Mexican Caribbean. Fish Cent Res Rep 11:227-235

Anderson MJ (2001) A new method for non-parametric multivariate analysis of variance. Austral Ecol 26:32-46

Anderson MJ (2005) PERMANOVA: a FORTRAN computer program for permutational multivariate analysis of variance. University of Auckland, Auckland

Anderson MJ, Connell SD, Gillanders BM, Diebel CE, Blom WM, Saunders JE, Landers TJ (2005) Relationships between taxonomic resolution and spatial scales of multivariate variation. J Anim Ecol 74:636-646

> Arias-González E (1998) Trophic models of protected and unprotected coral reef ecosystems in the South of the Mexican Caribbean. J Fish Biol 53:236-255

Bochdansky AB, Bollens SM (2004) Relevant scales in zoo- 
plankton ecology: distribution, feeding and reproduction of the copepod Acartia hudsonica in response to thinlayers of the diatom Skeletonema costatum. Limnol Oceanogr 49:625-636

Candela J, Tahahara S, Crepon M, Barnier B, Sheinbaum J (2003) Yucatan Channel flow: observations versus CLIPPER ATL6 and MERCATOR PAM models. J Geophys Res 108:3385

Coronado C, Candela J, Iglesias-Prieto R, Sheinbaum J, López M, Ocampo-Torres J (2007) On the circulation in the Puerto Morelos fringing reef lagoon. Coral Reefs 26:149-163

Daly KL, Smith W (1993) Physical-biological interactions influencing marine plankton. Annu Rev Ecol Syst 24: 555-585

Folt CL, Burns CW (1999) Biological drivers of zooplankton patchiness. Trends Ecol Evol 14:300-305

Gasca R, Alvarez-Cadena N, Suárez-Morales E (1996) Chaetognath assemblages in the Mexican Caribbean Sea (1991). Caribb Mar Stud 5:41-50

Genin A, Jaffe JS, Reef R, Richter C, Franks PJS (2005) Swimming against the flow: a mechanism of zooplankton aggregation. Science 308:860-862

- Giesecke R, González HE (2004) Feeding of Sagitta enflata and vertical distribution of chaetognaths in relation to low oxygen concentrations. J Plankton Res 26:475-486

Graham WM, Pages F, Hamner WM (2001) A physical context for gelatinous zooplankton aggregations: a review. Hydrobiologia 451:199-212

Haury LR, McGowan JS, Wiebe PH (1978) Patterns and processes in the time and space scales for plankton distribution. In: Steel JH (ed) Spatial patterns in plankton communities. Plenum Press, New York, p 277-327

Hearn CJ (1999) Wave-breaking hydrodynamics within coral reef systems and the effect of changing relative sea level. J Geophys Res 104:30007-30019

Hernández-Flores RM (2003) Report on a collection of chaetognaths from Banco Chinchorro, Mexican Caribbean Sea. Bull Mar Sci 73:123-131

Hogan JD, Mora C (2005) Experimental analysis of the contribution of swimming and drifting to the displacement of reef fish larvae. Mar Biol 147:1213-1220

Levin S (1992) The problem of pattern and scale in ecology. Ecology 73:1943-1967

Mackas DL, Sefton H, Miller C, Raich A (1993) Vertical habitat partitioning by large calanoid copepods in the oceanic

Editorial responsibility: Peter Verity,

Savannah, Georgia, USA subarctic Pacific during spring. Prog Oceanogr 32: 259-294

Mann KH, Lazier JRN (2006) Dynamics of marine ecosystems: biological-physical interactions in the oceans. Blackwell Publishing, Boston, MA

Merino IM, Otero DL (1991) Atlas ambiental costero, Puerto Morelos-Quintana Roo. Centro de Investigaciones de Quintana Roo (CIQRO), Chetumal

Nagai N, Tadokoro N, Kuroda K, Sugimoto T (2006) Occurrence characteristics of chaetognath species along the PM transect in the Japan Sea during 1972-2002. J Oceanogr 62:597-606

> Noda M, Ikeda I, Ueno S, Hashimoto H, Gushima K (1998) Enrichment of coastal zooplankton communities by drifting zooplankton patches from the Kuroshio front. Mar Ecol Prog Ser 170:55-65

Nùñez-Lara E, Arias-González E, Legendre P (2005) Spatial patterns of Yucatán reef fish communities: testing models using a multi-scale survey design. J Exp Mar Biol Ecol 324:157-169

Pinel-Alloul B (1995) Spatial heterogeneity as mutiscale characteristic of zooplankton community. Hydrobiologia 300-301:17-42

Roberts HH, Wilson PA, Lugo-Fernández A (1992) Biologic and geologic responses to physical processes: examples from modern reef systems of the Caribbean-Atlantic region. Cont Shelf Res 12:809-834

Sabatès A, Gili JM, Pagès F (1989) Relationship between zooplankton distribution, geographic characteristics and hydrographic patterns off the Catalan coast. Mar Biol 103: 153-159

Saiz E, Kiørboe T (1995) Predatory and suspension feeding of the copepod Acartia tonsa in turbulent environments. Mar Ecol Prog Ser 122:147-158

Sampey A, McKinnon D, Meekan MG, McCormick MI (2007) Glimpse into guts: overview of the feeding of larvae of tropical shorefishes. Mar Ecol Prog Ser 339:243-257

Suárez-Morales E, Gasca R (1996) Planktonic copepods of Bahia de la Ascención Caribbean coast of Mexico: a seasonal survey. Crustaceana 69:162-174

Suárez-Morales E, Gasca R (2000) The planktonic copepod community at Mahahual Reef, western Caribbean. Bull Mar Sci 66:255-267

Tzella A, Haynes PH (2007) Small-scale spatial structure in plankton distribution. Biogeosciences 4:173-179

Submitted: May 19, 2008; Accepted: October 6, 2008

Proofs received from author(s): December 19, 2008 